\title{
Analysis of Factors Affecting Stress in the Elderly Women
}

\author{
Yun-Jung Kang ${ }^{*}$ and Gil-Hyun Lee ${ }^{\dagger ; *}$ \\ Department of Clinical Laboratory Science, Kyungwoon University, Gumi 39160, Korea
}

\begin{abstract}
The purpose of this study is to identify the factors influencing the stress of the elderly women by various tools and to provide basic data for adaptation to the aging women. For this purpose, stress was measured by stress measuring equipment (HRV) and stress measurement questionnaire (SRI) in 31 elderly women over 60 years old. In summary, the results of this study suggest that the worse the subjective health, and when there is a spouse, it predicts a stress. In order to reduce the stress of elderly women based on these results, physical health management and environmental factors that can enhance the intimacy between husband and wife are also necessary.
\end{abstract}

Key Words: Elderly woman, Stress, Subjective health, Spouse

\section{서 론}

통계청에 따르면, 2015년 우리나라의 65세 이상 인구 는 657 만 명으로 전체 인구의 $13.2 \%$ 를 차지하는데, 이는 2005년보다 약 220 만 4천 명 증가한 수치다. 이와 같은 추세라면 우리나라는 2020년에는 노인 인구비 $15.7 \%$ 로 고령사회(aged society), 2030년에는 24.3\%로 초고령사회 (hyper aged society), 2040년에는 32.3\%로 노인중심사회가 될 것으로 예상된다(Kostat, 2015). 고령화가 심화되는 상 황은 우리사회가 노인이라는 대상에 대해 이전과는 다른 새로운 개념으로 접근해야 함을 의미한다. 통계적 예측치 만 가지고 계산하더라도 향후 5년 이내에 우리는 유소년 의 수보다 더 많은 노인들을 부양해야 한다. 이러한 상황 에서 노인은 막대한 사회적 비용이 소요될 집단으로 인식 되면서 미리 준비되고 관리되어야 할 대상으로 적극적으 로 다뤄진다. 더욱이 노인여성은 평균수명의 연장과 더불 어 남성보다 더 오래 살게 됨으로써 노인여성이 차지하는 비율이 높으며(Chae and Ha, 1999), 그에 따라 노인여성은
노인문제에서 관심을 가져야 할 주요 대상이 될 것으로 전망한다.

노화과정에서 발생하는 노인의 생활스트레스는 의존성 증가와 독립성 상실이 주요 원인으로 노인의 정신건강에 부정적인 요인으로 작용된다(Fiksenbaum et al., 2006). 스 트레스는 심리적 질환인 우울과도 밀접한 관련이 있어, 노인의 우울수준을 결정하는 주된 원인이 된다(Bolger et al., 1989). 노년기 우울은 만성질환, 인지기능 손상, 신체 기능상실 및 의학적 상태의 악화를 가져와(Aloxopoulos, 2005), 식욕감퇴나 수면장애, 활동저하 등을 초래하여 삶 의 질을 더욱 저하시키게 된다(Seo and Han, 2006). 특히 수면장애는 만성적인 피로감, 낙상, 운동실조 및 각종사고 를 일으키며, 다시 우울이나 불안과 같은 심리적인 문제 를 유발하는 악순환이 일어날 수 있다(Kozier et al., 2004). 노인들의 스트레스에 의한 수면장애의 경우 노인여성이 남성보다 신체적, 심리적, 환경적 모든 요인에서 더 많은 수면방해를 받고 있으며, 수면의 질 또한 낮은 것으로 나 타났다(Floyd, 1993). 또한 노인여성은 다산과 과중한 가 사노동으로 인한 신체적인 스트레스가 높을 뿐만 아니라

Received: September 18, 2018 / Revised: November 12, 2018 / Accepted: November 13, 2018

* Professor.

†Corresponding author: Gil-Hyun Lee. Department of Clinical Laboratory Science, Kyungwoon University, Gumi 39160, Korea.

Tel: +82-54-479-4114, Fax: +82-54-479-1308, e-mail: rokmagnum@ naver.com

(C) The Korean Society for Biomedical Laboratory Sciences. All rights reserved.

(c) This is an Open Access article distributed under the terms of the Creative Commons Attribution Non-Commercial License (http://creativecommons.org/licenses/by-nc/3.0/) which permits unrestricted non-commercial use, distribution, and reproduction in any medium, provided the original work is properly cited. 
(Lee and Lee, 2002), 평생을 가족관계 및 돌봄자로서의 역 할을 유지하다가 노인이 되면서 변화된 상황에 적응하기 가 힘들어 남성보다 더 높은 스트레스를 겪는 것으로 나 타났다(Shin and Kim, 2003). 이처럼 노인여성의 스트레스 가 중요한 의미를 가지고 있음에도 불구하고 폐경을 전후 한 중년여성들의 스트레스 관련 선행연구가 대다수이고, 노인여성의 스트레스 관련 영향요인에 관한 연구는 미흡 한 실정이다. 또한 연구가 있다고 하더라도 종속변수인 스트레스 측정을 설문지에 국한하여 연구되어 왔다. 본 연 구는 스트레스 측정 설문지(SRI: stress response inventory) 뿐만 아니라 신뢰성 있는 지표 심박동수 변이도(HRV: heart rate variability)를 이용한 스트레스 측정기로 스트레스 점수를 종속변수로 분석하여 보다 객관적인 스트레스 점 수로 연구하였다.

노인여성은 노인남성에 비해 스트레스가 더 높고, 노년 기의 스트레스는 정신건강 뿐만 아니라 신체건강의 약화 를 초래하여 노년기 삶의 질에 부정적인 결과를 가져 올 수 있기 때문에 노인의 스트레스에 대한 이해는 만족스런 노년생활을 위해 매우 중요한 일이라 판단된다. 따라서 본 연구는 노인여성에게 미치는 스트레스 영향요인을 다양한 도구로 규명하여 노후적응을 위한 기초자료를 제시하고자 한다.

\section{연구 및 방법}

\section{스트레스 반응 정도의 평가}

객관적 지표: 스트레스 측정 장비, 심박동수 변이도(HRV: heart rate variability): 심박동수 변이도(HRV: heart rate variability) 측정은 심박변이 측정용 맥파계인 MAX PULSE (Medicore Co Ltd. Korea)를 사용하였다. 심박동수 변이도 (HRV: heart rate variability)는 일중 변동을 보이므로, 이 영 향을 통제하기 위해 측정은 오전 8 시에서 12 시 사이에 실 시하였으며, 측정 시 외적 환경에 의하여 자율신경계가 영향을 받지 않도록 하기 위하여 실험실의 온도는 20 $25^{\circ} \mathrm{C}$ 를 유지하였고, 조명이 밝고 조용한 방에서 실시하였 으며, 연구대상자는 환자용 의자에 편안히 앉은 후 안정 이 되기를 기다린 후 좌우 손목부위와 좌측 발목부위에 각각 전극(eletrodes)을 부착하여 5 분간 측정하였다. 결과 분석은 기기에 내장된 장비를 이용하여 각종 지표를 산출 하였다.

\section{주관적 지표: 스트레스 측정 설문지(SRI: stress response}

inventory): 스트레스의 반응 정도를 평가하기 위하여 고 경봉등이 개발한 스트레스 측정 설문지(SRI: stress response inventory)를 이용하였다(Koh et al., 2000). SRI는 총 39문항 7 개의 하위척도로 구성되어 있으며, 감정적, 신체적, 인지 적, 행동적 스트레스 반응들을 포함하고 있다. 하위척도는 긴장 6 문항, 공격성 4 문항, 신체화 3 문항, 분노 6 문항, 우 울 8 문항, 피로 5 문항, 좌절 7 문항으로 구성되었다. 각 문 항은 0 4점까지의 5점 척도로 구성되어 있으며, 최저 0점 에서 최고 156점으로 점수가 높을수록 더 높은 정서적, 신 체적, 인지적, 행동적 스트레스 반응을 의미한다(Fig. 1).

\section{연구대상자}

본 연구는 지역사회에 거주하는 60세 이상의 노인여성 총 31 명을 대상으로 이루어졌다. 시설에 있는 노인을 제 외하고 일반 노인을 대상으로 하여 경제적 상태나 건강상 태의 수준이 과장되지 않도록 하였고, 장비 사용법에 능 숙한 실험자들이 스트레스 측정 장비로 스트레스를 측정 을 하였으며, 사전에 교육받은 면접원들이 일대일 면접을 통해 자료를 수집하였다. 본 연구는 경운대학교에서 기관 생명윤리위원회의 자체 심의를 받아 시행되었다.

\section{자료분석 방법}

통계분석은 전산코딩 후 AMOS 20.0 프로그램을 이용 하였으며 사용된 통계기법은 다음과 같다. 첫째, 기초통 계를 위해 빈도분석 및 기술통계를 실시하였다. 둘째, 표본 특성에 따른 차이를 알아보기 위해 Wilcoxon test와 Kruskal-Wallis test를 실시하였다. 셋째, 변수간의 관계를 알 아보기 위해 상관관계분석을 실시하였다. 넷째, 설명변수 와 종속변수의 영향관계를 알아보기 위해 step-wise 방식 회귀분석을 실시하였다.

\section{결 과}

\section{일반적 특성}

표본 특성은 Table 1 과 같다. 조사대상자는 총 31 명으 로 대다수 60대(77.4\%)에 해당했으며, 70세 이상 고령자 는 7명(22.6\%)으로 나타났다. 교육수준은 대다수가 무학 $(41.9 \%)$ 이거나 초졸(41.9\%)이었으며, 중졸 $(6.5 \%)$ 과 고졸 $(9.7 \%)$ 도 있었으나 그 이상의 학력자는 없는 것으로 나타 났다. 현재 동거중인 배우자 유무는 없음 $(80.6 \%)$ 이 가장 많았고, 있음 $(19.4 \%)$ 은 6명에 불과했다. 주관적 건강에 대 해서는 '나쁨'이 13명(41.9\%)으로 가장 많았고, 좋음(19.4\%), 


\begin{tabular}{|c|c|c|c|c|c|}
\hline & $\begin{array}{l}\text { Strongly } \\
\text { disagree }\end{array}$ & Disagree & Uncertain & Agree & $\begin{array}{c}\text { Strongly } \\
\text { agree }\end{array}$ \\
\hline Many mistakes in work. & $\square$ & $\square$ & $\square$ & $\square$ & $\square$ \\
\hline Do not want to work. & $\square$ & $\square$ & $\square$ & $\square$ & $\square$ \\
\hline Breasts are frustrating. & $\square$ & $\square$ & $\square$ & $\square$ & $\square$ \\
\hline Get angry. & $\square$ & $\square$ & $\square$ & $\square$ & $\square$ \\
\hline Feel nervous. & $\square$ & $\square$ & $\square$ & $\square$ & $\square$ \\
\hline Not digest it. & $\square$ & $\square$ & $\square$ & $\square$ & $\square$ \\
\hline Stomach pain. & $\square$ & $\square$ & $\square$ & $\square$ & $\square$ \\
\hline Want to scream. & $\square$ & $\square$ & $\square$ & $\square$ & $\square$ \\
\hline A sigh comes out. & $\square$ & $\square$ & $\square$ & $\square$ & $\square$ \\
\hline Feel messy. & $\square$ & $\square$ & $\square$ & $\square$ & $\square$ \\
\hline Everything is annoying. & $\square$ & $\square$ & $\square$ & $\square$ & $\square$ \\
\hline The worldly thoughts arise. & $\square$ & $\square$ & $\square$ & $\square$ & $\square$ \\
\hline Easy to feel fatigue. & $\square$ & $\square$ & $\square$ & $\square$ & $\square$ \\
\hline Whole body is weakened. & $\square$ & $\square$ & $\square$ & $\square$ & $\square$ \\
\hline Lost confidence. & $\square$ & $\square$ & $\square$ & $\square$ & $\square$ \\
\hline The body tremble. & $\square$ & $\square$ & $\square$ & $\square$ & $\square$ \\
\hline Want to hit someone. & $\square$ & $\square$ & $\square$ & $\square$ & $\square$ \\
\hline Not motivated. & $\square$ & $\square$ & $\square$ & $\square$ & $\square$ \\
\hline Want to cry. & $\square$ & $\square$ & $\square$ & $\square$ & $\square$ \\
\hline The nerves became sharp. & $\square$ & $\square$ & $\square$ & $\square$ & $\square$ \\
\hline No views on what I do. & $\square$ & $\square$ & $\square$ & $\square$ & $\square$ \\
\hline Feel hollow. & $\square$ & $\square$ & $\square$ & $\square$ & $\square$ \\
\hline Hate someone. & $\square$ & $\square$ & $\square$ & $\square$ & $\square$ \\
\hline Can not break out of one thought. & $\square$ & $\square$ & $\square$ & $\square$ & $\square$ \\
\hline Voice has grown. & $\square$ & $\square$ & $\square$ & $\square$ & $\square$ \\
\hline In a hurry. & $\square$ & $\square$ & $\square$ & $\square$ & $\square$ \\
\hline Action is tough (Abusive driving, swearing). & $\square$ & $\square$ & $\square$ & $\square$ & $\square$ \\
\hline Want to break something. & $\square$ & $\square$ & $\square$ & $\square$ & $\square$ \\
\hline Conversation is gone. & $\square$ & $\square$ & $\square$ & $\square$ & $\square$ \\
\hline Head hurts. & $\square$ & $\square$ & $\square$ & $\square$ & $\square$ \\
\hline Heart is palpitate. & $\square$ & $\square$ & $\square$ & $\square$ & $\square$ \\
\hline Want to kill someone. & $\square$ & $\square$ & $\square$ & $\square$ & $\square$ \\
\hline Face is red or hot. & $\square$ & $\square$ & $\square$ & $\square$ & $\square$ \\
\hline Be bored. & $\square$ & $\square$ & $\square$ & $\square$ & $\square$ \\
\hline Be impatient. & $\square$ & $\square$ & $\square$ & $\square$ & $\square$ \\
\hline Facial expression becomes hard. & $\square$ & $\square$ & $\square$ & $\square$ & $\square$ \\
\hline I am a worthless person. & $\square$ & $\square$ & $\square$ & $\square$ & $\square$ \\
\hline Do not want to move. & $\square$ & $\square$ & $\square$ & $\square$ & $\square$ \\
\hline
\end{tabular}

Fig. 1. SRI: stress response inventory 
매우 좋음(16.1\%), 보통(12.9\%), 매우 나쁨 $(9.7 \%)$ 순으로 나타났다. 질병력은 고혈압(48.4\%), 이상지질혈증(45.2\%), 뇌졸중 $(6.5 \%)$, 심근경색(16.1\%), 협심증 $(9.7 \%)$ 등으로 나타
났다. 건강습관으로 음주와 흡연을 측정하였는데 흡연자 는 없었으며, 음주빈도(최근 1년간)는 전혀 없음(67.7\%)이 가장 많았고, 한 달 1회 미만(16.1\%), 한 달 1회(9.7\%), 한

Table 1. General characteristics

\begin{tabular}{|c|c|c|c|c|}
\hline & Description & & $\mathrm{N}($ total $=31)$ & $\%$ \\
\hline \multirow{9}{*}{ Demographic characteristics } & \multirow{3}{*}{ Age } & $60 \sim 64$ & 12 & 38.7 \\
\hline & & $65 \sim 69$ & 12 & 38.7 \\
\hline & & $>70$ & 7 & 22.6 \\
\hline & \multirow{4}{*}{ Education level } & None & 13 & 41.9 \\
\hline & & Elementary school & 13 & 41.9 \\
\hline & & Middle school & 2 & 6.5 \\
\hline & & High school & 3 & 9.7 \\
\hline & \multirow{2}{*}{ Marital status } & No & 25 & 80.6 \\
\hline & & Yes & 6 & 19.4 \\
\hline \multirow{5}{*}{ Subjective health } & \multirow{5}{*}{ Subjective health } & Very good & 5 & 16.1 \\
\hline & & Good & 6 & 19.4 \\
\hline & & Average & 4 & 12.9 \\
\hline & & $\mathrm{Bad}$ & 13 & 41.9 \\
\hline & & Very bad & 3 & 9.7 \\
\hline \multirow{10}{*}{ Disease history } & \multirow{2}{*}{ Hypertension } & No & 16 & 51.6 \\
\hline & & Yes & 15 & 48.4 \\
\hline & \multirow{2}{*}{ Dyslipidemia } & No & 17 & 54.8 \\
\hline & & Yes & 14 & 45.2 \\
\hline & \multirow{2}{*}{ Stroke } & No & 29 & 93.5 \\
\hline & & Yes & 2 & 6.5 \\
\hline & \multirow{2}{*}{ Myocardial infarction } & No & 26 & 83.9 \\
\hline & & Yes & 5 & 16.1 \\
\hline & \multirow{2}{*}{ Angina pectoris } & No & 28 & 90.3 \\
\hline & & Yes & 3 & 9.7 \\
\hline \multirow{4}{*}{ Health behavior } & \multirow{4}{*}{$\begin{array}{l}\text { Alcohol intake } \\
\text { (within recent } 1 \text { year) }\end{array}$} & Never & 21 & 67.7 \\
\hline & & $<1 /$ month & 5 & 16.1 \\
\hline & & $1 /$ month & 3 & 9.7 \\
\hline & & $2 \sim 4 /$ month & 2 & 6.5 \\
\hline \multirow{8}{*}{ Physical exercise } & \multirow{2}{*}{ Vigorous activity } & No & 25 & 80.6 \\
\hline & & Yes & 6 & 19.4 \\
\hline & \multirow{2}{*}{ Moderate activity } & No & 18 & 58.1 \\
\hline & & Yes & 13 & 41.9 \\
\hline & \multirow{2}{*}{ Walking activity } & No & 9 & 29.0 \\
\hline & & Yes & 22 & 71.0 \\
\hline & \multirow{2}{*}{ Leisure activity } & No & 24 & 77.4 \\
\hline & & Yes & 7 & 22.6 \\
\hline
\end{tabular}


Table 2. Descriptive statistic of stress

\begin{tabular}{lllrrrr}
\hline \hline & Stress & N & Min. & Max. & \multicolumn{1}{c}{ Mean } & \multicolumn{1}{c}{ SD } \\
\hline \multirow{3}{*}{ Objective measure } & Stress score & 31 & 31 & 88 & 61.97 & 14.06 \\
& Physical stress & 31 & 1.00 & 4.00 & 2.45 & 0.81 \\
& Mental stress & 31 & 1.00 & 4.00 & 1.77 & 0.80 \\
\hline \multirow{5}{*}{ Subjective measure } & Tension & 31 & 1.00 & 3.67 & 1.39 & 0.64 \\
& Aggression & 31 & 1.00 & 1.75 & 1.06 & 0.18 \\
& Somatization & 31 & 1.00 & 3.67 & 1.66 & 0.75 \\
& Anger & 31 & 1.00 & 2.83 & 1.39 & 0.46 \\
& Depression & 31 & 1.00 & 3.75 & 1.45 & 0.70 \\
& Fatigue & 31 & 1.00 & 3.20 & 1.79 & 0.71 \\
& Frustration & 31 & 1.00 & 3.86 & 1.46 & 0.68 \\
& SRI total & 31 & 39.00 & 128.00 & 56.61 & 19.69 \\
\hline
\end{tabular}

Objective Measure: HRV, Subjective measure: SRI

달 2 4회(6.5\%) 등으로 나타났다. 신체 활동은 고강도 활 동(19.4\%), 중등도 활동(41.9\%), 걷기 활동(71.0\%). 여가신 체 활동(22.6\%) 등으로 나타났다(Table 1).

\section{스트레스의 영향요인}

스트레스의 측정은 객관적 지표(HRV (heart rate variability); 이하 $\mathrm{OM}$ )와 주관적 지표(SRI (stress response inventory); 이하 SM)를 함께 측정하였으며, 객관적 지표에 는 스트레스 점수, 신체적 스트레스, 정신적 스트레스의 하위영역이 있으며, 주관적 지표는 SRI의 7개 하위영역(긴 장, 공격성, 신체화, 분노, 우울, 피로, 좌절)과 총점을 변수 로 사용하였다. 적은 수의 표본 내에서 각각의 측정결과 는 의미를 갖지 못하므로 변수간의 관계에서 변동량을 통 해 스트레스의 변화를 살펴보고자 한다(Table 2).

\section{단변량분석 결과}

일반적 특성에 따른 스트레스 측정결과는 다음 Table 3 과 같다. 변수의 개수가 많기 때문에 $(14 \times 11)$ 유의수준 $P<.05$ 하에서 유의미한 결과로 나온 내용만 간추려 제 시하였다. 먼저 현재 동거중인 배우자 여부에 따라서는 신체화(SM), 우울(SM), 피로(SM), 스트레스 측정 설문지 (SRI: stress response inventory) 총점(SM)에서 유의미한 결 과가 나타났다. 즉, 현재 배우자가 있는 경우 그렇지 않은 노인여성보다 위 하위영역의 스트레스가 높은 것으로 나 타났다. 주관적 건강에 따라서는 스트레스 점수 $(\mathrm{OM})$, 긴 장(SM), 분노(SM), 우울(SM), 피로(SM), 좌절(SM), SRI 총
점(SM)에서 유의미한 차이가 있는 것으로 나타났다. 즉, 주관적 건강이 나쁠수록 위 하위영역의 스트레스가 증가 하는 것으로 나타났다. 심근경색 질병력에 따라서는 스트 레스 점수 $(\mathrm{OM})$ 와 우울(SM)에서 유의미한 차이가 나타났 으며, 심근경색을 않고 있는 경우 그렇지 않은 경우에 비 해 스트레스가 높은 것으로 나타났다. 협심증의 경우에는 스트레스 점수 $(\mathrm{OM})$ 와 신체적 스트레스 $(\mathrm{OM})$ 에서 유의미 한 차이가 나타났으며, 협심증을 않고 있는 경우 스트레 스가 더 높은 것을 알 수 있다. 걷기신체 활동에 따라서는 정신적 스트레스 $(\mathrm{OM})$ 에서만 유의미한 차이가 나타났으며, 꾸준히 걷기 활동을 하는 집단이 그렿지 않은 집단에 비 해 스트레스가 낮은 것으로 나타났다. 여가신체 활동에 따라서는 긴장(SM)과 우울(SM)에서 유의미한 차이가 나 타났으며, 여가신체활동을 하는 집단의 스트레스가 더 낮 은 것으로 나타났다(Table 3).

\section{상관관계 결과}

위 단변량분석 결과에 따라 유의미하게 나온 설명변수 들과 스트레스 측정변인들과의 관계를 상관관계분석을 통 해 살펴보았으며 그 결과는 Table 4 와 같다. 이 때 연령은 범주형이 아닌 실제 연령(만 나이)을 투입하여 함께 살펴 보았다. 먼저 연령은 정신적 스트레스 $(\mathrm{OM})$ 와 정의 상관이 있는 것으로 나타났으며, 배우자가 있는 경우 공격성 $(\mathrm{SM})$, 신체화(SM), 우울(SM), 피로(SM), 좌절(SM), 스트레스 측 정 설문지(SRI: stress response inventory) 총점(SM)의 스트 레스가 높은 것으로 나타났다. 주관적 건강은 나쁘다고 
Table 3. Stress by general statistics

\begin{tabular}{|c|c|c|c|c|c|c|}
\hline & & & $\mathrm{N}$ & $\mathrm{M} \pm \mathrm{SD}$ & $\mathrm{t} / \mathrm{F}$ & $P$-value \\
\hline \multirow{8}{*}{ By marital status } & \multirow{2}{*}{ Somatization } & No & 25 & $1.52 \pm 0.68$ & \multirow{2}{*}{-2.176} & \multirow{2}{*}{.038} \\
\hline & & Yes & 6 & $2.22 \pm 0.83$ & & \\
\hline & \multirow{2}{*}{ Depression } & No & 25 & $1.32 \pm 0.58$ & \multirow{2}{*}{-2.281} & \multirow{2}{*}{.030} \\
\hline & & Yes & 6 & $2.00 \pm 0.93$ & & \\
\hline & \multirow{2}{*}{ Fatigue } & No & 25 & $1.65 \pm 0.68$ & \multirow{2}{*}{-2.389} & \multirow{2}{*}{.024} \\
\hline & & Yes & 6 & $2.37 \pm 0.56$ & & \\
\hline & \multirow{2}{*}{ SRI total } & No & 25 & $52.40 \pm 15.01$ & \multirow{2}{*}{-2.668} & \multirow{2}{*}{.012} \\
\hline & & Yes & 6 & $74.17 \pm 28.07$ & & \\
\hline & \multirow{5}{*}{ Stress score } & Very good & 5 & $47.80 \pm 10.48$ & \multirow{5}{*}{2.753} & \multirow{5}{*}{.045} \\
\hline & & Good & 6 & $57.33 \pm 15.86$ & & \\
\hline & & Average & 4 & $72.00 \pm 10.49$ & & \\
\hline & & $\mathrm{Bad}$ & 13 & $65.15 \pm 11.82$ & & \\
\hline & & Very bad & 3 & $67.67 \pm 15.31$ & & \\
\hline & \multirow{5}{*}{ Tension } & Very good & 5 & $1.03 \pm 0.07$ & \multirow{5}{*}{4.540} & \multirow{5}{*}{.006} \\
\hline & & Good & 6 & $1.17 \pm 0.21$ & & \\
\hline & & Average & 4 & $1.38 \pm 0.64$ & & \\
\hline & & $\mathrm{Bad}$ & 13 & $1.37 \pm 0.45$ & & \\
\hline & & Very bad & 3 & $2.56 \pm 1.27$ & & \\
\hline & \multirow{10}{*}{ Depression } & Very good & 5 & $1.07 \pm 0.15$ & \multirow{5}{*}{3.178} & \multirow{5}{*}{.030} \\
\hline & & Good & 6 & $1.28 \pm 0.31$ & & \\
\hline & & Average & 4 & $1.25 \pm 0.40$ & & \\
\hline & & $\mathrm{Bad}$ & 13 & $1.45 \pm 0.38$ & & \\
\hline & & Very bad & 3 & $2.06 \pm 0.84$ & & \\
\hline & & Very good & 5 & $1.20 \pm 0.27$ & \multirow{5}{*}{3.195} & \\
\hline & & Good & 6 & $1.15 \pm 0.23$ & & \\
\hline \multirow[t]{18}{*}{ By sub. health } & & Average & 4 & $1.28 \pm 0.26$ & & .029 \\
\hline & & $\mathrm{Bad}$ & 13 & $1.48 \pm 0.68$ & & \\
\hline & & Very bad & 3 & $2.58 \pm 1.34$ & & \\
\hline & & Very good & 5 & $1.16 \pm 0.22$ & & \\
\hline & & Good & 6 & $1.60 \pm 0.55$ & & \\
\hline & Fatigue & Average & 4 & $1.30 \pm 0.35$ & 6.601 & .001 \\
\hline & & $\mathrm{Bad}$ & 13 & $2.00 \pm 0.66$ & & \\
\hline & & Very bad & 3 & $2.93 \pm 0.31$ & & \\
\hline & & Very good & 5 & $1.14 \pm 0.25$ & & \\
\hline & & Good & 6 & $1.14 \pm 0.22$ & & \\
\hline & Frustration & Average & 4 & $1.18 \pm 0.14$ & 3.098 & .028 \\
\hline & & $\mathrm{Bad}$ & 13 & $1.58 \pm 0.68$ & & \\
\hline & & Very bad & 3 & $2.43 \pm 1.27$ & & \\
\hline & & Very good & 5 & $43.80 \pm 5.76$ & & \\
\hline & & Good & 6 & $48.33 \pm 9.58$ & & \\
\hline & SRI total & Average & 4 & $50.75 \pm 6.13$ & 5.253 & .003 \\
\hline & & $\mathrm{Bad}$ & 13 & $59.00 \pm 16.52$ & & \\
\hline & & Very bad & 3 & $92.00 \pm 35.04$ & & \\
\hline
\end{tabular}


Table 3. Stress by general statistics (Continued)

\begin{tabular}{|c|c|c|c|c|c|c|}
\hline & & & $\mathrm{N}$ & $\mathrm{M} \pm \mathrm{SD}$ & $\mathrm{t} / \mathrm{F}$ & $P$-value \\
\hline \multirow{4}{*}{ By MI } & \multirow{2}{*}{ Stress score } & No & 26 & $59.50 \pm 12.78$ & \multirow{2}{*}{-2.398} & \multirow{2}{*}{.023} \\
\hline & & Yes & 5 & $74.80 \pm 14.70$ & & \\
\hline & \multirow{2}{*}{ Depression } & No & 26 & $1.33 \pm 0.58$ & \multirow{2}{*}{-2.328} & \multirow{2}{*}{.027} \\
\hline & & Yes & 5 & $2.08 \pm 0.98$ & & \\
\hline \multirow{4}{*}{ By AP } & \multirow{2}{*}{ Stress score } & No & 28 & $60.32 \pm 13.33$ & \multirow{2}{*}{-2.102} & \multirow{2}{*}{.037} \\
\hline & & Yes & 3 & $77.33 \pm 13.28$ & & \\
\hline & \multirow{2}{*}{ Phy. stress } & No & 28 & $2.36 \pm 0.73$ & \multirow{2}{*}{-2.093} & \multirow{2}{*}{.045} \\
\hline & & Yes & 3 & $3.33 \pm 1.15$ & & \\
\hline \multirow{2}{*}{ By walking activity } & \multirow{2}{*}{ Mental stress } & No & 9 & $2.22 \pm 0.97$ & \multirow{2}{*}{2.092} & \multirow{2}{*}{.045} \\
\hline & & Yes & 22 & $1.59 \pm 0.67$ & & \\
\hline \multirow{4}{*}{ By leisure activity } & \multirow{2}{*}{ Tension } & No & 24 & $1.49 \pm 0.70$ & \multirow{2}{*}{2.754} & \multirow{2}{*}{.010} \\
\hline & & Yes & 7 & $1.07 \pm 0.13$ & & \\
\hline & \multirow{2}{*}{ Depression } & No & 24 & $1.56 \pm 0.76$ & \multirow{2}{*}{3.031} & \multirow{2}{*}{.005} \\
\hline & & Yes & 7 & $1.07 \pm 0.12$ & & \\
\hline
\end{tabular}

Table 4. Correlations among variables

\begin{tabular}{lccccccc}
\hline \hline & Age & $\begin{array}{c}\text { Marital } \\
\text { status }\end{array}$ & $\begin{array}{c}\text { Subjective } \\
\text { health }\end{array}$ & MI & AP & Walking & $\begin{array}{c}\text { Leisure } \\
\text { activity }\end{array}$ \\
\hline Stress score & -0.227 & 0.025 & $\mathbf{. 4 4}^{*}$ & $\mathbf{. 4 0 7}^{*}$ & $\mathbf{. 3 6 4}^{*}$ & 0.338 & 0.141 \\
Physical stress & -0.248 & 0.03 & 0.305 & $\mathbf{. 4 1 2}^{*}$ & $\mathbf{. 3 6 2}^{*}$ & 0.273 & 0.178 \\
Mental stress & $\mathbf{. 4 0 1 ^ { * }}$ & 0.14 & -0.201 & -0.097 & -0.044 & $\mathbf{. 3 6 2}^{*}$ & -0.041 \\
\hline Tension & -0.013 & 0.301 & $\mathbf{. 4 6}^{* *}$ & 0.238 & 0.288 & 0.079 & -0.276 \\
Aggression & -0.24 & $\mathbf{. 4 2 2}^{*}$ & 0.119 & -0.14 & $\mathbf{. 3 5 9}$ & 0.205 & 0.046 \\
Somatization & 0.151 & $\mathbf{. 3 7 5}^{*}$ & 0.353 & 0.164 & 0.25 & -0.137 & -0.201 \\
Anger & 0 & 0.245 & $\mathbf{. 4 8 7}^{* *}$ & 0.273 & 0.285 & 0.129 & -0.151 \\
Depression & 0.116 & $\mathbf{. 3 9}^{*}$ & $\mathbf{. 4 2 2}^{*}$ & $\mathbf{. 3 9 7}$ & 0.261 & 0.161 & -0.298 \\
Fatigue & -0.184 & $\mathbf{. 4 0 6}^{*}$ & $\mathbf{. 6 1 4}^{* *}$ & 0.209 & 0.037 & 0.11 & 0.076 \\
Frustration & -0.004 & $\mathbf{. 4 3}^{*}$ & $\mathbf{. 4 7 3 *}^{* *}$ & 0.283 & 0.314 & 0.011 & -0.171 \\
SRI total & 0.005 & $\mathbf{. 4 4}^{*}$ & $\mathbf{. 5 4 8}^{* *}$ & 0.317 & 0.294 & 0.094 & -0.208 \\
\hline
\end{tabular}

$* P<.05, * * P<.01$

$\mathrm{MI}=$ myocardial infarction, $\mathrm{AP}=$ angina pectoris

인식할수록 스트레스 점수(OM), 긴장(SM), 분노(SM), 우 울(SM), 피로(SM), 좌절(SM), SRI 총점(SM)이 증가하였다. 심근경색은 스트레스 점수 $(\mathrm{OM})$, 신체적 스트레스( $\mathrm{OM})$, 우 울(SM)과 정의 상관이 있으며, 협심증은 스트레스 점수 $(\mathrm{OM})$, 신체적 스트레스 $(\mathrm{OM})$, 공격성 $(\mathrm{SM})$ 과 정의 상관이 있는 것으로 나타났다. 걷기 운동은 정신적 스트레스( $(\mathrm{OM})$ 를 감소시키는 것으로 나타났으나, 여가신체 활동은 스트 레스 측정변인과 유의미한 상관이 없는 것으로 나타났다
(Table 4).

\section{Step-wise 회귀분석 결과}

Table 3, 4의 결과에 따라 각 스트레스 요인에 대하여 유 의미한 상관을 갖는 설명변수들을 투입해 회귀분석을 실 시하였다. 다중회귀분석에서는 투입되는 변수의 수나 설 명변수간의 영향력에 따라 분석 결과가 달라지므로 가장 유의미한 설명변수부터 순차적으로 투입하는 step-wis 방 
식을 채택함으로써 중요하지 않은 변수를 제거하였다. 선 택된 요인들을 살펴보면 주관적 건강과 건강상태가 스트 레스를 가장 잘 설명하는 것으로 나타났다.

먼저 스트레스 점수에 대하여는 주관적 건강만이 유의 미하게 스트레스를 예측하는 것으로 나타났으며, 주관적 건강이 나쁠수록 스트레스를 $\beta=.447$ 만큼 증가시키는 것 으로 나타났다 $(P<.05)$. 신체적 스트레스에는 질병력 중 심 근경색이 유의미하게 예측하고 있으며, 심근경색 유병환 자는 그렇지 않은 노인여성에 비해 $\beta=.412$ 만큼 스트레스 가 높은 것으로 나타났다 $(P<.05)$. 정신적 스트레스는 연령 의 영향력이 가장 크며, 연령이 증가할수록 정신적 스트 레스는 $\beta=.401$ 만큼 증가하는 것으로 나타났다 $(P<.05)$. 긴 장은 주관적 건강의 영향을 받으며, 주관적 건강이 나쁠 수록 $\beta=.469$ 만큼 증가하는 것으로 나타났다 $(P<.01)$. 공격 성은 결혼상태의 영향을 받으며, 현재 동거중인 배우자가 있는 경우 그렇지 않은 노인여성들보다 $\beta=.422$ 만큼 증가 하는 것으로 나타났다 $(P<.05)$. 신체화 역시 결혼상태의 영 향을 받으며, 동거중인 배우자가 있는 경우 $\beta=.375$ 만큼 증가하였다 $(P<.05)$. 분노는 주관적 건강이 유의미하게 예 측하고 있으며, 주관적 건강이 나쁠수록 $\beta=.487$ 만큼 증가 하는 것으로 나타났다 $(P<.01)$. 우울은 주관적 건강, 결혼
상태의 순으로 함께 영향을 미치며, 주관적 건강이 나쁠 수록 $\beta=.390$ 만큼 $(P<.05)$, 배우자가 있는 경우 $\beta=.355$ 만큼 $(P<.05)$ 우울을 증가시키는 것으로 나타났다. 피로 또한 주관적 건강과 결혼상태가 함께 영향을 미치며, 주관적 건 강이 나쁠수록 $\beta=.582$ 만큼 $(P<.001)$, 배우자가 있는 경우 $\beta=.353$ 만큼 $(P<.05)$ 증가시키는 것으로 나타났다. 좌절 역 시 주관적 건강과 결혼상태의 영향을 받으며, 주관적 건 강이 나쁠수록 $\beta=.436$ 만큼 $(P<.01)$, 배우자가 있는 경우 $\beta=.413$ 만큼 $(P<.01)$ 증가시키는 것으로 나타났다. SRI 총 점은 주관적 건강과 결혼상태가 함께 유의미하게 예측하 고 있으며, 주관적 건강이 나쁠수록 $\beta=.512$ 만큼 $(P<.001)$, 배우자가 있는 경우 $\beta=.397$ 만큼 $(P<.05)$ 증가시키는 것으 로 나타났다(Table 5).

\section{고 찰}

스트레스의 반응 정도를 평가하기 위해서는 심박동수 변이(HRV: heart rate variability)를 이용한 스트레스 장비 측정 방법과 설문지 형태의 스트레스 반응척도 방법이 있 다. 본 연구에서는 스트레스의 영향요인을 다각도에서 연 구하기 위하여 두 가지 방법을 모두 활용하였다. 스트레

Table 5. Determinants of stress

\begin{tabular}{|c|c|c|c|c|c|c|}
\hline \multirow{2}{*}{ Dependent variable } & \multirow{2}{*}{ Independent variable } & \multirow{2}{*}{$\beta$} & \multirow{2}{*}{$t$} & \multirow{2}{*}{$P$-value } & \multicolumn{2}{|c|}{ Satistics } \\
\hline & & & & & adj. R2 & $F$ \\
\hline Stress score & Sub. health & .447 & 2.690 & .012 & .172 & $7.238^{*}$ \\
\hline Phs. stress & MI & .412 & 2.434 & .021 & .141 & $5.926^{*}$ \\
\hline Men. stress & Age & .401 & 2.355 & .025 & .132 & $5.547^{*}$ \\
\hline Tension & Sub. health & .469 & 2.857 & .008 & .193 & $8.163^{* *}$ \\
\hline Aggression & Marital status & .422 & 2.507 & .018 & .150 & $6.284^{*}$ \\
\hline Somatization & Marital status & .375 & 2.176 & .038 & .111 & $4.736^{*}$ \\
\hline Anger & Sub. health & .487 & 3.006 & .005 & .211 & $9.034^{* *}$ \\
\hline \multirow{2}{*}{ Depression } & Sub. health & .390 & 2.459 & .020 & \multirow{2}{*}{.253} & \multirow{2}{*}{$6.078^{* * *}$} \\
\hline & Marital status & .355 & 2.239 & .033 & & \\
\hline \multirow{2}{*}{ Fatigue } & Sub. health & .582 & 4.337 & $<.001$ & \multirow{2}{*}{.465} & \multirow{2}{*}{$14.014^{* * *}$} \\
\hline & Marital status & .353 & 2.630 & .014 & & \\
\hline \multirow{2}{*}{ Frustration } & Sub. health & .436 & 2.949 & .006 & \multirow{2}{*}{.350} & \multirow{2}{*}{$9.081^{* * *}$} \\
\hline & Marital status & .413 & 2.797 & .009 & & \\
\hline \multirow{2}{*}{ SRI total } & Sub. health & .512 & 3.665 & .001 & \multirow{2}{*}{.419} & \multirow{2}{*}{$11.797^{* * *}$} \\
\hline & Marital status & .397 & 2.843 & .008 & & \\
\hline
\end{tabular}

$* P<.05, * * P<.01, * * * P<.001$

Analyzed by step-wise regression

$\mathrm{MI}=$ myocardial infarction 
스 장비로 측정한 스트레스를 객관적 스트레스 측정, $\mathrm{OM}$ (Objective Measure)으로 표기하였으며, 설문지 형태의 스트 레스 측정을 주관적 스트레스 측정, SM (Subjective measure)으로 표기하였다. 스트레스는 대개 주관적인 증상이 어서 이에 대한 객관적인 평가는 어렵다. 심박동수 변이 도(HRV: heart rate variability)를 이용한 스트레스 장비 측정 방법은 스트레스를 가장 객관적으로 평가할 수 있는 방법 이라고 할 수 있다. 심박동수 변이란 생리적인 심박동수 변동이 얼마나 잘 나타나는가 하는 변동 정도를 나타내는 것으로 자율신경계의 정상적인 상호작용을 의미한다. 자 율신경계가 심장질환에 미치는 영향을 평가하기 위해 심 박동수 변이도(HRV: heart rate variability) 분석으로 활용할 수 있다. 심박동수 변이도(HRV: heart rate variability)는 심장 의 자율신경계의 활성을 나타내는 지표로 심혈관질환의 이환율 및 사망률과 관련이 있다(Forslund et al., 2002). 심 박동수 변이도(HRV: heart rate variability)에서 나타나는 수 치인 $\mathrm{SDNN}$ (standard deviation of all normal R-R intervals)은 전체 자율신경반응을 제시한다. 그리고 저주파수(low frequency; LF)는 교감신경과 부교감신경에 의한 자극을 동시 에 반영하지만 주로 교감신경계의 활성도를 반영한다. 고 주파수(high frequency; $\mathrm{HF}$ )는 부교감신경 자극이 작용하며 $\mathrm{LF} / \mathrm{HF}$ 비는 자율신경 활동의 균형을 나타낸다(Heartmath research center, 1996). 일반적으로 스트레스가 높은 군에서 교감신경계의 과반응에 의해 심박동수 변이가 감소하며, 다른 위험인자와 함께 심장질환의 예측지표로 유의하다고 알려져 있다(Bosner and Kleiger, 1995). 이렇듯 다각도로 스 트레스를 측정하였으며, 가장 유의미한 설명변수부터 순 차적으로 투입하는 step-wise 회귀분석 결과는 주관적 건 강과 결혼상태가 가장 주요한 예측인자로 나왔다. 즉, 주 관적 건강이 나쁠수록 배우자가 있는 경우 유의미하게 스 트레스를 예측하는 것으로 나타났다.

첫째, 주관적 건강이 나쁠수록 유의미하게 스트레스를 예측한 선행연구들을 살펴보면 근로자를 대상으로 주관적 건강과 직무스트레스에 관한 연구는 많으나, 노인을 대상 으로 주관적 건강과 스트레스에 관련한 연구는 미흡한 상 태이며, 주관적 건강과 우울의 관련성에 관한 연구는 활 발히 진행되어 왔다. 노인의 스트레스와 우울은 정적 상 관관계로 노인생활에서 스트레스는 우울의 잠재적인 위 험요인으로 보고 있다(Lee, 2007). 그렇기 때문에 주관적 건강과 우울에 관련한 선행연구들도 살펴보는 것이 타당 하다. 연구들의 결과를 보면, 주관적 건강인식과 우울과의 관계는 자신의 신체건강수준을 높이 인식할수록 우울의
정도가 낮은 것으로 매우 일관된 결과를 보이고 있다(Hur and Yoo, 2002; Kim and Lee, 2010). 노인이 자신의 건강에 대한 긍정적 인식은 질병을 완화시키고 사회적 지원체계 에 대한 접근성을 높이는 반면, 건강에 대한 부정적 평가 는 활동성을 감소시키고, 대인관계의 어려움으로 인한 심 리적 위축 등으로 스트레스, 우울의 유발요인이 되는 것 으로 보인다. 또한 주관적 건강인식은 단지 본인의 느낌 이나 생각이 아니고 실제 신체적 건강상태와 일치한다는 흥미로운 연구결과가 있다. 최의(Choi, 2016) 연구결과 주 관적 건강상태의 부정적인 응답은 연령대를 분석하지 않 은 모든 모델에서 건강문제의 부정적인 변화를 유의하게 예측하였다. 주관적 건강인식은 실제 건강상태의 대리변 수로 활용이 가능하다는 것이다. 즉 건강이 나빠지고 있 다고 본인이 주관적으로 느끼는 것이 실제 건강상태를 반 영한다는 것이다. 그러므로 주관적으로 인식하는 건강상 태는 실제 건강상태이며, 신체적으로 건강할 때 정신적 으로도 건강을 유지할 수 있다. 2017년 윤 등(Yoon et al., 2017)의 지역사회 주민들의 주관적 건강인식과 행복지수 의 관련성 연구에서는 주관적 건강수준이 높을수록, 행복 지수가 높아지는 관련성을 도출하였다.

둘째, 배우자가 있는 경우 유의미하게 스트레스를 예측 하였다. 노년기에는 배우자가 중요한 위치를 차지한다. 노 년기 부부갈등은 젊은 부부갈등과 차이가 있다. 젊은 부부 들이 가사분담과 의사결정과정에서의 권력에 대해 갈등을 경험하는 반면에 노년기 부부들은 자녀가 집을 떠남과 남 편의 퇴직에 따라 함께 보내는 시간이 많아지고 새로운 친밀성을 요구하므로 그에 적응하는 과정에서 갈등이 표 출된다고 한다(Yang and Im, 1998). 많은 연구들은(Tower and Kasl, 1996; Townsend and Franks, 1997) 노년기 부부관계 에서도 다른 가족생활주기의 부부들처럼 친밀감과 함께 갈등이 공존해 있음을 밝히고 있다. 특히 평균수명의 연 장으로 인해 과거보다 부부와 함께 보내는 시기가 길어진 노년기 관계는 이전에 해결되지 않은 갈등이 다시 표출되 면서 관계가 악화되거나 부부가 서로에게서 고립된 생활 을 영위한다(Yang and Im, 1998). 또한 노년기 부부간에 갈 등은 사회변화에 대한 수용 및 역할전환과 역할적응과정 에서 발생하기도 한다(Kim, 1995). 즉 현대사회에서 부부 관계는 많은 변화를 나타내고 있지만, 노인들은 아직도 가부장적 가치관이 상당히 남아있고, 부부관계의 개선을 위하여 변화를 원하는 부인과 가부장적 관계를 고수하는 남편과의 불일치는 부부간의 갈등을 유발하는 것으로 보 인다. 
본 연구결과 주관적 건강이 나쁠수록, 배우자가 있는 경 우 유의미하게 스트레스를 예측하는 결과를 볼 때, 노인 여성의 스트레스를 감소하기 위해서는 신체적 건강관리 와 부부간의 친밀감을 높여줄 수 있는 환경적 요인도 필 요한 것으로 생각된다.

\section{ACKNOWLEDGEMENT}

This work was supported by research fund from Kyungwoon university.

\section{CONFLICT OF INTEREST}

No potential conflict of interest relevant to this article was reported.

\section{REFERENCES}

Aloxopoulos GS. Depression in the elderly. Lancet. 2005. 365: 1961-1970.

Bolge N, Delongi A, Kessler RC, Schiling EA. Effects of daily stress on negative mood. J Pers Soc Psychol. 1989. 57: 808 -818.

Bosner MS, Kleiger RE. Heart rate variability and risk stratification after myocardial infarction. In: Malik M. Camm AJ (eds.): Heartrate variability. Armont, NY. Futura Publishing Co. 1995.

Chae OH, Ha GY. The Living Conditions and Problems of the elderly Women in Chonbuk rural area. Institute for Life Resource Development ment. 1999. 1: 86-105.

Choi YH. Is Subjective Health Reliable as a Proxy Variable for True Health? A Comparison of Self-rated Health and Selfassessed Change in Health among Middle-aged and Older South Koreans. Health and Social Welfare Review. 2016. 36: 431-459.

Fiksenbaum KM, Greenglass ER. Eaton J. Perceived social support, hassles and coping among elderly. Am J Epidemiol. 2006. 25: 17-30.

Floyd JA. The use of across-method triangulation in the study of sleep concerns is healthy older adults. Adv Nurse Sci 1993. 16: $70-80$

Forslund L, Bjorkander I, Ericson M, Held C, Kahan T, Rehnqvist N, Hjemdahl P. Prognostic implications of autonomic function assessed by analysis of catecholamines and heart rate variability in stable angina pectoris. Heart (British Cardiac Society). 2002. 87: 415-422.

Heartmath research cente, Autonomic assessment report-A comprehensive heart rate variability analysis. 1996 institute of heartmath. 1996.

Hur JS, Yoo SH. Determinants of Depression among Elderly Persons. Mental Health \& Social Work. 2002. 13: 7-35.

Kim JM, Lee JA. Depression and Health Status in the Elderly. Journal of the Korean Gerontological Society. 2010. 30: 1311 $-1327$.

Kim TH. Gerontology. 1995. pp 48-58. Gyomoon Publishers. Seoul, Korea.

Koh KB, Kim CH, Park KJ. Development of the stress response inventory. The Korean J of Neuropsychiatric Association. 2000. 39: 707-719.

Kozier B, Erb G, Berman A, Snyder S. Fundamentals of nursing: Concepts, process, and practice (7th ed.). 2004. New Jersey: Prentice-Hall College Div.

Lee IJ. Sex Differences in the Effects of Psychosocial Factors on Depression and Life satisfaction of Older Persons. Journal of Welfare for the Aged. 2007. 36: 159-180.

Lee SS, Lee KJ. The Stress, Social Support and Psychological Well - being of the Elderly. Journal of the Korea Gerontological Society. 2002. 22: 1-20.

Seo HS, Han YH. Effects of Health-Related Indexes on Life Satisfaction for the Elderly People. Korean Journal of Research in Gerontology. 2006. 15: 159-170.

Shin KL, Kim JS. A Study on the Relationship between Stress and Depression in Elderly Women. Journal of Korean Gerontological Nursing. 2003. 5: 29-37.

Tower R, Kasl S. Gender, Marital closeness, and depressive symptoms in elderly couple. Journal of Gerontology. 1996. 51: 115 $-129$.

Townsend AL, Franks M. Quality of relationships between elderly spouses: Influence on spouse caregivers subjective effectiveness. Family relations. 1997. 46: 33-39.

URL:http://www.kostat.go.kr/portal/korea/kor_nw/2/1/index.board?bmode $=$ read\&aSeq $=348565.2015$.

Yang, JG, Im SY. A Study on the Marital Conflict and Depression in Old Age. J Korean Home Econ Assoc. 1998. 36: 1-12.

Yoon HS, Chun JH, Chae YJ. The relevance of subjective health recognition and happiness index of local community residents (Using community health survey data 2014). Journal of Korean Academy of Oral Health. 2017. 41: 194-200.

https://doi.org/10.15616/BSL.2018.24.4.319

Cite this article as: Kang YJ, Lee GH. Analysis of Factors Affecting Stress in the Elderly Women. Biomedical Science Letters. 2018. 24: 319-328. 